\title{
B cells in lung cancer - not just a bystander cell: a literature review
}

\author{
Tracy L. Leong ${ }^{1,2,3,4}$, Vanessa L. Bryant ${ }^{1,4,5}$
}

${ }^{1}$ The Walter and Eliza Hall Institute of Medical Research, Parkville, Victoria, Australia; ${ }^{2}$ Department of Respiratory and Sleep Medicine, Austin Health, Heidelberg, Victoria, Australia; ${ }^{3}$ Institute of Breathing and Sleep, Heidelberg, Victoria, Australia; ${ }^{4}$ Faculty of Medicine, Dentistry and Health Sciences, The University of Melbourne, Parkville, Victoria, Australia; ${ }^{5}$ Department of Allergy and Clinical Immunology, Royal Melbourne Hospital, Parkville, Victoria, Australia

Contributions: (I) Conception and design: Both authors; (II) Administrative support: Both authors; (III) Provision of study materials or patients: Both authors; (IV) Collection and assembly of data: Both authors; (V) Data analysis and interpretation: Both authors; (VI) Manuscript writing: Both authors; (VII) Final approval of manuscript: Both authors.

Correspondence to: Dr. Tracy L. Leong. Department of Respiratory Medicine, Austin Health, 145 Studley Road, Heidelberg, Victoria 3084, Australia. Email: tracy.leong@austin.org.au.

\begin{abstract}
Metastatic lung cancer represents a significant global issue where it is responsible for the most cancer diagnoses and deaths worldwide. Treatment for advanced lung cancer has undergone a series of paradigm shifts from chemotherapy to targeted molecular agents to the most recent immunotherapy strategies. The most successful of the latter involves antibodies that block inhibitory receptors on tumor infiltrating $\mathrm{T}$ cells, thereby enhancing $\mathrm{T}$ cell activity against tumor cells. However, only a subset of patients demonstrate durable responses to these drugs and treatment resistance is common. Emerging evidence suggests that a critical role exists for B cells as more than a bystander immune cell in the tumor microenvironment (TME). However, this role is likely context-specific where B cells comprise distinct subtypes with unique effector functions that may result in anti- or pro-tumor effects. As such, the balance between various $\mathrm{B}$ cell subtypes affects the net B cell impact upon tumor immunity. To date, the factors needed to polarize B cell function toward anti-tumor activity are unclear. Understanding B cell biology in the lung cancer setting will help redefine and refine treatment strategies to augment anti-tumor immunity. This article presents a review of the literature describing the current knowledge of the development and function of B cells, and explores their role in lung cancer and potential as an immunotherapeutic strategy and as a predictive marker for response to immune checkpoint blockade.
\end{abstract}

Keywords: B cell; B lymphocyte; immune checkpoint inhibitors (ICIs); immunotherapy; lung cancer

Submitted Jun 30, 2020. Accepted for publication Jan 19, 2021.

doi: $10.21037 /$ tlcr-20-788

View this article at: http://dx.doi.org/10.21037/tlcr-20-788

\section{Introduction}

Worldwide, lung cancer is the most frequently diagnosed malignancy and the leading cause of cancer death (1). This is largely due to over $50 \%$ of non-small cell lung cancer (NSCLC) patients presenting with disease that has metastasized to distant organs, where life expectancy under chemotherapy has generally not exceeded 12 to 18 months (2). In this group, systemic treatment is the mainstay and has undergone a series of paradigm shifts where options have evolved from chemotherapy to targeted molecular agents to the most recent immunotherapy strategies (3).

Approximately two-thirds of the lung tumor microenvironment (TME) immune cells are composed of $\mathrm{T}$ and $\mathrm{B}$ cells (4). The effects of lung cancer infiltrating $\mathrm{T}$ cells have been extensively studied. As a result, the most successful immune-oncology approaches in lung cancer consist of antibodies that block inhibitory receptors 
("checkpoints") that are upregulated on T cells infiltrating the tumor, thereby enhancing the patient's $T$ cells to act against the tumor cells $(5,6)$. However, while preliminary findings of these $\mathrm{T}$ cell-targeted inhibitors have been promising, a significant proportion of patients with NSCLC do not achieve sustained disease control. This indicates the need to understand other immune cells in the TME in order to develop alternative therapeutic approaches (7).

Recent evidence suggests a critical role exists for B cells in lung cancer where studies indicate that proliferating B cells are observed in $35 \%$ of lung cancer (8), and where they are present at all stages of lung cancer development with variations across clinical stages and histological subtypes $(9,10)$. However, relative to T cells, knowledge of B cell biology in lung cancer remains less well developed. The purpose of this review is to provide a comprehensive overview of the phenotypic diversity and roles of B cells in lung cancer, and to offer insight into potential mechanisms by which they may be utilized as an integral component of immunotherapeutic strategies and as biomarkers of treatment responsiveness. We present the following article in accordance with the Narrative Review reporting checklist (available at http://dx.doi.org/10.21037/tlcr-20-788).

\section{Methods}

A literature search was conducted through PubMed and cross references, from inception to April 2020, to identify publications describing the nature and function of $\mathrm{B}$ cells in lung cancer. Search strategies were developed using subject headings and text words based on two terms: "B cells" and "lung cancer".

\section{Discussion}

\section{$B$ cells develop in the bone marrow to give rise to diverse effector cells}

B cells are the central players of humoral immunity through their capacity for immunoglobulin (antibody) production (11). Generation of antibodies is the end result of a complex and highly regulated process of B cell development and signalling that involves many subpopulations that can be defined by anatomical location, cell morphology, specific cell surface markers and immunoglobulin heavy $(\mathrm{H})$ chain and light $(\mathrm{L})$ chain gene loci arrangements.

In the first instance, B cells originate in the bone marrow from common lymphoid progenitor cells. With the acquisition of specific cell surface markers, they develop sequentially into early pro-B cells, late pro-B cells, large pre-B cells, small pre-B cells, before migrating to the spleen as immature B cells. As immature transitional (T1) B cells then exit the bone marrow and migrate to the spleen, they transition to a T2 B cell subtype. T2 cells further differentiate into follicular (FO) B cells, the most abundant and are found in the B cell areas of lymph nodes, Peyer's patches and spleen; and marginal zone (MZ) B cells, which reside in the marginal sinus of the spleen (11).

B cells not only differ in their geographic location, but in their mode of activation through $\mathrm{T}$ cell-independent or T cell-dependent pathways (12). Polysaccharide or lipid antigens can stimulate MZ B cells directly, independent of $\mathrm{T}$ cells, to become short-lived plasma cells that produce low affinity (mostly non class-switched $\operatorname{IgM}$ ) antibodies. Conversely, $\mathrm{T}$ cell-dependent responses are associated with protein antigens that are processed and presented to cognate FO T helper cells through MHC class II molecules, which in turn via CD40 engagement, IL-21 and IL-4 production, directly modulate the outcomes of the immune response.

Activation of naïve B cells occurs following encounter with their cognate antigen, which specifically binds to the $\mathrm{B}$ cell receptor (BCR). Once activated, MZ B cells may initiate an extrafollicular response and differentiate into plasmablasts that produce antibodies that are generally weak affinity and short-lived (13). Alternatively, activated FO B cells may enter a lymphoid follicle and initiate a germinal center (GC) response. GC are highly organised, transient tissue structures formed in secondary lymphoid tissue during the course of the immune response. The exquisitely coordinated movement of lymphocytes in these structures is directed by antigen-specific recognition, activation, and chemokines to bring into close contact antigen-specific B and $\mathrm{T}$ cells that define adaptive immunity and memory. Here, activated B cells may undergo somatic hypermutation and affinity maturation selection, where mutations caused by the enzyme activation-induced cytidine deaminase (AID) are randomly introduced into variable regions of the BCR to further diversify the immunological repertoire and those with increased affinity for antigen preferentially selected for clonal expansion (14). B cells may also undergo AIDinduced immunoglobulin class switching where their BCR isotype is switched from $\operatorname{IgM}$ to downstream isotypes $\operatorname{IgG}, \operatorname{IgA}$ or $\operatorname{IgE}$ to alter effector functions $(15,16)$. The specific class of switching and differentiation into antibodysecreting cells is directly influenced by the $\mathrm{T}$ cell derived cytokine signals (17). 
A key role of GC B cells is the differentiation into memory B cells, which can circulate or reside in secondary lymphoid organs as quiescent cells for decades (18) poised to respond rapidly to subsequent exposure. Alternatively, they may terminally differentiate into long-lived plasma cells, which preferentially migrate to the bone marrow and are capable of secreting large amounts of high affinity antibody upon subsequent encounters (19).

\section{$B$ cells are critical for antigen presentation, antibody production, and immune homeostasis}

$\mathrm{B}$ cells are capable of directly internalizing antigen via the $\mathrm{BCR}$, with subsequent presentation and activation of $\mathrm{T}$ cells in the context of MHC class II molecules. B cells and dendritic cells provide a further co-stimulatory signal for expansion of effector $\mathrm{T}$ cell populations via cross-linking of CD40 with CD40 ligand on $\mathrm{CD}^{+} \mathrm{T}$ cells, which in turn induces additional second co-stimulatory signals of CD86 and CD80 expression on the B cell surface (11).

Specific recognition and binding of a foreign antigen to the BCR also results in a downstream signaling cascade mediated by membrane bound protein tyrosine kinases, including spleen tyrosine kinase (STK), Bruton tyrosine kinase (BTK), and PI3K. Together, these processes activate $\mathrm{NF}-\mathrm{\kappa B}$ signaling and other key processes essential for $\mathrm{B}$ cell proliferation and differentiation into antigen-specific memory B cells and antibody secreting plasma cells.

B cells also play a role in immune regulation via secretion of anti-inflammatory cytokines, which can affect $\mathrm{T}$ cells, dendritic cells, lymphoid tissue reorganization and neogenesis. These so-called regulatory B cells (Bregs) have been poorly characterized, but have been shown to inhibit T cell-mediated immunity through production of inhibitory cytokines such as IL-10, IL-35 and transforming growth factor beta (TGF- $\beta)(20,21)$.

\section{$B$ cells represent an important proportion of infiltrating cells in solid cancers}

Tumor-infiltrating lymphocytes (TILs) are now known to play a significant role in tumor progression. While the effects of $T$ cells have been extensively studied, the function of $\mathrm{B}$ cells in this context remains poorly defined. However, there is evidence that $\mathrm{B}$ cells have been found to represent a critical component of infiltrating immune cells in a variety of solid tumors, including breast cancer and melanoma where they comprise almost half of the total infiltrating lymphocyte population $(11,12)$.

In breast cancer, multiple studies report that $\mathrm{CD} 20^{+} \mathrm{B}$ cells are associated with favorable outcomes, particularly in specific breast cancer subtypes, such as the highly proliferative basal-like and HER2 ${ }^{+}$tumors (22). However, there is simultaneous evidence suggesting that tumorinfiltrating B cells may be linked with worse prognosis, particularly in breast ductal carcinoma in situ, which is a microinvasive form of breast cancer, suggesting that $\mathrm{CD} 20^{+}$ $\mathrm{B}$ cells may play a tumor-promoting role in early-stage disease (22).

In melanoma, several studies have reported improved outcomes in tumors that have a high $\mathrm{CD} 20^{+} \mathrm{B}$ cell density, specifically, better overall survival and lower likelihood of metastasis (23). However, the converse is also apparent in the context where accumulation of $\mathrm{CD} 138^{+}$terminally differentiated (long-lived) plasma cells is associated with poor prognosis in cutaneous melanoma (23). Furthermore, the immunoglobulin isotype appears to have relevance where elevated $\mathrm{IgG} 4^{+}$plasma cells were predictive of disease progression (23).

Movement of B cells and other immune cells in response to tumor, or indeed any immunological threat, is a carefully regulated process, balanced by coordinated expression of chemokine and chemokine receptors expression to ensure appropriate migration and positioning of immune cells in tissues. Expression of chemokines and chemokine receptors mediate anti-tumor immunity by directing the migration of $\mathrm{B}$ cells and other leukocytes to the tumor site. The outcome of this migratory response is context-specific, as it may involve trafficking of leukocytes that have tumor-promoting or anti-tumor activities.

A number of chemokine/chemokine receptor antagonists are currently in clinical trials, either alone, or for example, in combination with immune checkpoint inhibitor (ICI) pembrolizumab in advanced solid tumors or metastatic melanoma (24). Chemokine-mediated regulation of immune cell recruitment into tumor sites as well as was recently reviewed, as well as review of emerging evidence that support the direct targeting of chemokines/chemokine receptors as a strategy to disrupt tumor promoting microenvironment towards anti-tumor immunity including potentially inhibiting expression of CCR4 to deplete regulatory $T$ cells in lung cancer $(24,25)$.

To address the conflicting findings regarding the effect of B cells on tumor growth, a recent systematic review of 69 studies was conducted across 19 human cancers to address the prognostic significance of tumor-infiltrating B cells (26). 
Table 1 Tumor infiltrating B cell subsets in human lung cancer

\begin{tabular}{|c|c|}
\hline Tumor infiltrating B cell subset & Marker $\left(\mathrm{CD} 45^{+} \mathrm{CD} 19^{+}\right)$ \\
\hline Germinal center B (GC B) & $\mathrm{Bcl}^{+} \mathrm{CD}^{2} 0^{+} / \mathrm{Ki} 7^{+} \mathrm{CD} 20^{+}(17)$ \\
\hline Naïve B & $\mathrm{CD}_{20} \mathrm{C}^{\mathrm{C}} 38^{+/-} \mathrm{CD} 27^{-} \lg \mathrm{D}^{+}(17)$ \\
\hline Class switched memory B & $\mathrm{CD} 20^{+} \mathrm{CD}_{38^{+/}} \mathrm{CD} 27^{+} \lg \mathrm{D}^{-} \lg \mathrm{G} / \mathrm{A} / \mathrm{E}^{+}(17)$ \\
\hline Plasmablast & CD38 ${ }^{\text {hi }} C D 24^{\text {hi }} C D 27^{\text {int }}(17)$ \\
\hline Plasma cell & $\mathrm{CD}_{20}{ }^{-\mathrm{CD}} 27^{++} \mathrm{CD} 8^{+} / \mathrm{CD} 138^{+}(17)$ \\
\hline \multicolumn{2}{|l|}{ Regulatory B } \\
\hline B10 & $\mathrm{CD} 20^{+} \mathrm{CD} 24^{\mathrm{hi}} \mathrm{CD} 27^{+} \mathrm{IL}-10^{+}(31,32)$ \\
\hline $\mathrm{B}$ regulatory $1(\mathrm{Br} 1)$ & $\mathrm{CD} 20^{+} \mathrm{CD} 25^{\text {hi }} \mathrm{CD} 71^{\text {hi }} \mathrm{CD} 73^{\mathrm{lo}} \mathrm{IL}-10^{+} \operatorname{lgG} 4^{+}(35)$ \\
\hline
\end{tabular}

The majority of studies reported positive or neutral prognostic effects, with only a minority reporting a negative effect. Furthermore, in studies that assessed the effects of $\mathrm{B}$ and $\mathrm{T}$ cells, the prognostic effects of both lymphocyte subsets were largely concordant, suggesting that B cells may work in concert with $\mathrm{T}$ cells to exert anti-tumor functions.

\section{B cells play dual roles in lung cancer}

In lung cancer, tumor infiltrating B cells have similarly been observed, with their phenotype differing according to clinical stage and histological subtype $(17,27,28)$. Within the tumor, B cells can interact with $\mathrm{T}$ cells in tertiary lymphoid structures (TLS), which are GCs forming as ectopic foci of $\mathrm{B}$ cells, mature dendritic cells and $\mathrm{T}$ cells in cancer tissue $(17,29,30)$. In this context, B cells are associated with dual roles in both anti- and pro-tumor immunity (11). As such, the balance between various $B$ cell subtypes affects the net B cell impact upon tumor immunity (Table 1, Figure 1).

\section{B cells and anti-tumor immunity}

A number of studies have found $\mathrm{CD} 20^{+} \mathrm{B}$ cell infiltration to be associated with favorable prognosis in NSCLC $(8,17,27,28)$. For example, in a comparative study of 196 patients with early-stage untreated NSCLC and advanced stage NSCLC treated with neoadjuvant chemotherapy, increased $\mathrm{B}$ cells were associated with prolonged disease- free survival (17).

The favorable clinical outcomes of tumor-infiltrating B cells have been best documented in the adenocarcinoma subgroup of lung cancer where analysis of RNA sequencing data from The Cancer Genome Atlas (TCGA) database that revealed that high levels of expression of $\mathrm{B}$ cell and plasma cell signature genes correlated with increased overall survival in lung adenocarcinoma (36). Furthermore, concurrent analysis of programmed death ligand 1 (PD-L1), which is the primary target of current immunomodulatory agents, has identified a significant and positive correlation with B cell levels. This suggests that $B$ cell infiltration may represent a crucial factor in clinical efficacy of anti-PD-L1 therapies in lung adenocarcinoma patients (37). The prognostic relevance of B cells is less well documented in lung squamous cell carcinoma with only a single study demonstrating a correlation between CD20 $0^{+} \mathrm{B}$ cells and improved diseasespecific survival exclusively in squamous cell carcinoma (27). As such, the mechanisms of $\mathrm{B}$ cell control of tumors are poorly defined and may differ among lung cancer histological subgroups due to differences in composition and behavior of the $\mathrm{B}$ cell subsets that comprise the infiltrate.

B cells that specifically express CD19, CD20, and CD11c can act as antigen presenting cells (APCs) (38,39). In NSCLC models, infiltrating $\mathrm{B}$ cells have been shown to present antigen to $\mathrm{CD}^{+} \mathrm{T}$ cells, resulting in robust $\mathrm{T}$ cell effector responses. In this setting, two subpopulations of $\mathrm{B}$ cells were identified: activated $\left(\mathrm{CD} 19^{+} \mathrm{CD} 20^{+} \mathrm{CD} 69^{+} \mathrm{CD} 27^{+} \mathrm{CD} 21^{+}\right)$ 

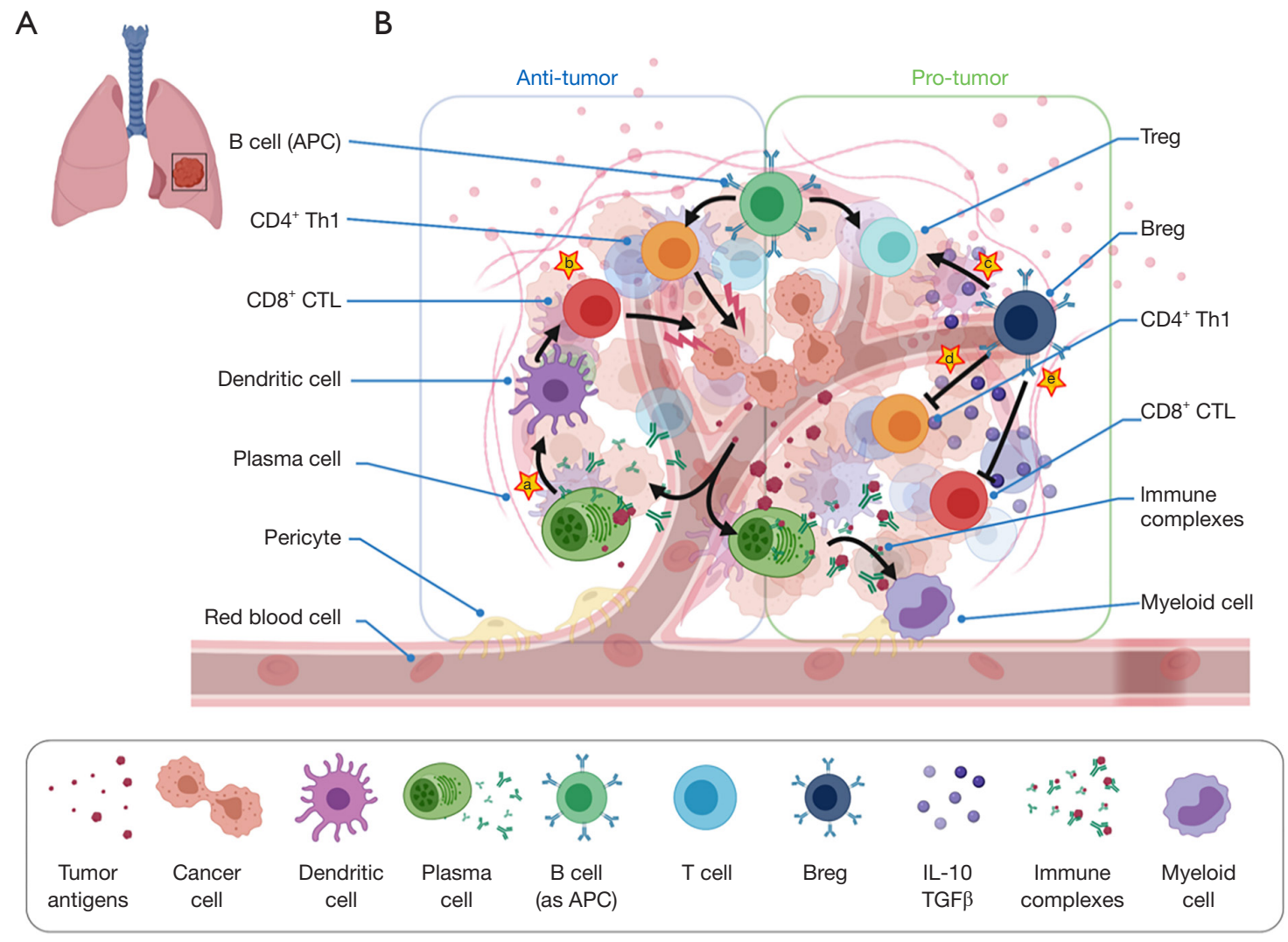

Figure 1 The dual role of B cells in the lung cancer microenvironment. (A) Primary tumor in the left lung. (B) Tumor cells and TME. Anti-tumor activities are mediated via APC function and antibody production. Pro-tumor activities are mediated via production of protumorigenic factors, activation of immunosuppressive T regulatory cells, and activation of myeloid-derived suppression cells. Pro-tumor activity is largely mediated by a specific subset of B regulatory cells. Sites for potential therapeutic targets are denoted yellow stars: (a) antigen-specific immunotherapeutic "vaccines" to induce B cell humoral response; (b) transfer of CD40 activated B cells that engage effector T cells; (c-e) specific inhibition of Bregs or IL-10. TME, tumor microenvironment; APC, antigen presenting cell; Th1, T helper type 1 cells; CTL, cytotoxic T lymphocyte; Treg, T regulatory cell; Breg, B regulatory cell.

or exhausted $\left(\mathrm{CD} 19^{+} \mathrm{CD} 20^{+} \mathrm{CD} 69^{+} \mathrm{CD} 27^{-} \mathrm{CD} 21^{-}\right)$. While activated B cell APCs could induce Th1 differentiation with anti-tumorigenic roles (e.g., IFN $\gamma$-producing $\mathrm{CD}^{+} \mathrm{T}$ cells), exhausted B cell APCs led to generation of a regulatory $\mathrm{T}$ cell phenotype $\left(\mathrm{Foxp} 3^{+} \mathrm{CD} 4^{+}\right)$with pro-tumorigenic functions $(38,40)$.

Tumor-associated antigens, such as LAGE-1, TP53, and NY-ESO-1, can trigger B cell-mediated antibody production (17). This has been demonstrated in an in vitro NSCLC model, where tumor antigen-specific B cell responses are evidenced by the production of tumorspecific antibody and the oligoclonality of TIL B cells in the TLS (40). Furthermore, B cells cultured from TLS have been shown to produce tumor-specific IgG and IgA, which are associated with favorable outcomes $(17,41)$. In turn, tumor-specific antibodies support killing of tumors through a range of pathways. In a study of murine models of large cell lung carcinoma, Mizukami et al. demonstrated that injection of tumor-specific antibodies resulted in complement cascade with tumor cell lysis (42). Furthermore, Carmi et al. showed that antibodies produced by B cells at the early stage of lung tumor development served to activate dendritic cells, which subsequently triggered a cytotoxic $\mathrm{T}$ cell response to control tumor growth (43). Lastly, B cell derived antibodies may play a role in triggering tumor cell phagocytosis by macrophages and granulocytes (11).

An important determinant of whether antibodies have anti-tumor effects is the antibody isotype generated. In cancer, the human IgG1 antibody isotype is of primary importance where it can bind to the constant fragment $\gamma$ 
Table 2 Breg phenotypes in human NSCLC

\begin{tabular}{|c|c|c|c|}
\hline Study & $\mathrm{N}$ & Phenotype & Mechanism of immunosuppression \\
\hline Lizotte et al., 2016 (59) & 51 & $\mathrm{CD}_{19^{+}} \mathrm{CD} 24^{\mathrm{hi}} \mathrm{CD} 38^{\mathrm{hi}} \mathrm{CD} 5^{+} \mathrm{CD} 1 \mathrm{~d}^{\mathrm{hi}} \mathrm{CD} 27^{+}$ & IL-10 \\
\hline Zhang et al., 2016 (60) & 9 & $\mathrm{CD} 19^{+} \mathrm{CD}^{+}$ & STAT3 via IL-10 \\
\hline Bruno et al., 2017 (40) & 62 & $\mathrm{CD}_{19}{ }^{+} \mathrm{CD} 2 \mathrm{O}^{+} \mathrm{CD} 69^{+} \mathrm{CD} 27^{-} \mathrm{CD} 21^{-}$ & Treg cells via IL-10 and TGF- $\beta$ \\
\hline
\end{tabular}

Breg, B regulatory cell; NSCLC, non-small cell lung cancer; Treg, T regulatory cell.

receptor $(\mathrm{Fc} \gamma \mathrm{R})$ and trigger antibody-dependent cellular cytotoxicity (ADCC), antibody-mediated phagocytosis, and complement-dependent cytotoxicity (44). Furthermore, $\mathrm{Fc} \gamma \mathrm{R}$ expressed on dendritic cells and macrophages may capture IgG-bound tumor antigens and present these to $\mathrm{T}$ cells. In addition, effector and memory B cells expressing IgG may also execute direct anti-tumor functions through production of granzyme B, tumor necrosis factor-related apoptosis-inducing ligand (TRAIL), and IFN $\gamma$. Support for these findings has been illustrated by using human RNA sequencing datasets from TCGA, where a high proportion of IgG1 isotype has been positively correlated with mutation burden in lung adenocarcinoma, thereby linking driver mutations and B cell response (45).

\section{B cells and pro-tumor immunity}

The beneficial impact of B cells on NSCLC outcomes has not been universally demonstrated $(10,46,47)$. More specifically, pro-tumor activity has been linked a specific immunosuppressive B cell subset known as IL-10 producing Bregs. These cells were initially defined by their ability to maintain immune tolerance and restore homeostasis following inflammation. Recent accumulating evidence supports a role for B cells in modulating the immune response to malignancy (48-50).

B cell mediated immune suppression with resultant tumor growth is thought to occur through a variety of mechanisms $(20,21,51,52)$. Production of suppressive cytokines such as IL-10, TGF- $\beta$, and IL-35 is welldocumented where IL-10 is capable of inhibiting the T cell mediated anti-tumor response, and TGF- $\beta$ facilitates conversion of naïve $\mathrm{CD}^{+} \mathrm{T}$ cells into Foxp $3^{+} \mathrm{T}$ regulatory cells (Tregs) that act to attenuate the anti-tumor immunity. In addition, Bregs may cause suppression of $T$ cells and Natural Killer (NK) cells, with subsequent expansion of
Tregs and myeloid-derived suppression cells (MDSCs). Furthermore, Bregs can promote the upregulation of negative immune checkpoint molecules such as PD-1 and PD-L1 that inhibit anti-tumor immunity. Lastly, STAT 3 signaling by Bregs have a role in mediating vascular endothelial growth factor (VEGF) and promoting tumor growth and metastasis via generation of Treg cells and angiogenesis $(53,54)$.

Breg infiltration has been observed in a range of solid tumor malignancies, including NSCLC, where significantly higher frequencies of peripheral Bregs $\left(\mathrm{CD} 19^{+} \mathrm{CD} 24 \mathrm{hiCD} 27^{+}\right)$and $\mathrm{CD} 19^{+} \mathrm{IL}-10^{+} \mathrm{B}$ cells have been observed compared with healthy controls (55).

However, characterization of Bregs in the context of malignancy has been challenging for a number of reasons. While similar B cell subpopulations have been shown to migrate to the tumor site, the signals that polarize B cells to a Breg phenotype are unclear (56). Furthermore, despite increasing literature describing subsets of B cells that exhibit regulatory properties, the precise phenotype and characteristic cell surface markers of Bregs in lung cancer are poorly understood (57). For example, while Bregs have conventionally been defined as $\mathrm{CD} 5^{+} \mathrm{CD} 24 \mathrm{hiCD} 27^{+} \mathrm{CD} 38$ hi (31), immature $\mathrm{B}$ cell populations have yielded Bregs characterized as $\mathrm{CD} 19^{+} \mathrm{CD} 24^{+} \mathrm{CD} 27^{+} \mathrm{IL}-10^{+}$and $\mathrm{CD} 19^{+} \mathrm{CD} 24 \mathrm{hiCD} 27 \mathrm{i}$ ntCD44highCD $138^{+} \mathrm{IL}-10^{+}$. To add to the complexity, animal models have been used to explore the profile and mechanisms of Bregs in promoting carcinogenesis, however their applicability to human disease has been limited by phenotypic and functional diversity of Bregs (58). As a result of these challenges, there are very few published studies that discuss the role of Bregs in human lung cancer (Table 2). There is a need to sub-stratify B cells into distinct developmental subsets as well as functionally in regulatory-, anti-, and pro-tumor functions. 


\section{The balance between anti-and pro-tumor activities of $B$ cells is likely to be influenced by the TME}

Tumor cells themselves can produce factors, cytokines or metabolites which directly impact the function of B cells. Additionally, tumor cells can secrete extracellular vesicles carrying mRNAs or proteins which can activate Breg populations (11).

Immune cells in the TME have been shown to also influence $\mathrm{B}$ cell migration, activation and differentiation. Anti-tumor activities may be reinforced though B cells and $\mathrm{T}$ cells. The former can produce CXCL13 and lymphotoxin via TLR4 signaling, which are factors required for the formation of lymphoid follicles and can support the formation of TLS, which in turn can generate the antitumor effects of $\mathrm{CD} 8^{+} \mathrm{T}$ cells $(62,63)$. $\mathrm{T}$ cells expressing IL-17 may enhance the anti-tumor effects of B cells by inducing $\mathrm{B}$ cell migration and increasing FAS/FASLdependent direct tumor cell killing by B cells (11). Protumor activities may be promoted by other cells of the TME, such as regulatory $T$ cells and MDSCs, by activating Bregs, decreasing antibody production, and killing antitumor B cells that have APC capabilities (11).

Given the role of B cells in inflammation homeostasis, factors such as tissue hypoxia are also likely to affect the balance between anti- and pro-B cell functions. Hypoxia is a hallmark of cancer where tumor cell proliferation causes vascular disorganization, with increased oxygen consumption and decreased oxygen supply. This condition results in production of hypoxia-inducible factors (HIFs) that facilitate adaptation of cells to the environment. HIFs can impact a broad range of cellular processes in immune cells, which are postulated to impact tumor growth. However, the role of these mechanisms on B cells in cancer remains poorly understood.

\section{Role of B cells in lung cancer treatment: current approaches and future potential}

With multi-faceted functions in tumor development, therapies that target B cells may offer opportunities to further personalize the approach to lung cancer management (Figure 1).

\section{Therapies activating $B$ cells}

Several strategies have been explored to harness the anti-tumor potential of B cells. Antigen-specific immunotherapeutic "vaccines" have been designed to induce a B cell humoral response. Antibodies produced by responding $\mathrm{B}$ cells may deliver therapeutic effects by direct target of tumor antigens (e.g., anti-CD20 in B cell related lymphoma/leukemia, anti-HER2 in breast cancer) or via immunomodulatory effects (e.g., anti-CTLA4, anti-PD-1/PDL-1, anti-LAG). They have the capacity to activate ADCC, phagocytosis, and complement-dependent cytotoxicity (64). In a randomized placebo-controlled phase 3 trial, the immunotherapeutic targeting the tumor antigen MAGE-A3 was assessed in NSCLC (65). While this monovalent agent did not increase disease-free survival, there remains tantalizing potential for multi-valent vaccines against personalized $\mathrm{B}$ cell antigens, akin to the model of the chimeric antigen receptor $\mathrm{T}$ cell (CART) therapy.

Targeted approaches for enhancing conventional B cells through transfer of stimulated B cell ligands has been shown to inhibit tumor growth and lung metastasis. For example, direct CD40:CD40L engagement induces the expression of a range of co-stimulatory molecules and cytokines that both activate $\mathrm{B}$ cells as well as naïve and memory $\mathrm{T}$ cells. The potential of these CD40-activated B cells has been tested in pre-clinical models of melanoma, lymphoma, breast tumor metastasis, and sarcoma (66). In another study, injection of activated B cells pre-stimulated with CpG DNA, a Tolllike receptor 9 (TLR9) ligand, has been similarly used in a model of lung metastasis to induce regression of disease (67).

\section{Therapies depleting or inbibiting $B$ cells}

As some B cell populations, particularly the Breg phenotype, are associated with tumor progression, agents to deplete or inhibit B cells may have therapeutic value. B cell depletion via anti-CD20 monoclonal antibody, Rituximab, is widely used for B-cell malignancies, but has also demonstrated antitumor activity in small series of patients with other cancers such as melanoma, colorectal carcinoma, and cutaneous $\mathrm{T}$ cell lymphoma (68-70). However, conflicting results have been reported in other studies with tumor growth observed after anti-CD20 therapy $(71,72)$. This is likely, in part due to the non-specific activity of B-cell depleting antibodies which do not distinguish between effector and regulator $\mathrm{B}$ cell subsets (73) and do not effectively target CD20 lowexpressing plasma cell subsets.

Therefore, specific inhibition of Bregs may be an effective strategy to influence the immunosuppressive TME without negatively impacting other B cell subpopulations that have beneficial anti-tumor properties. Bodogai et al. 
demonstrated that, in tumor-bearing mice, $\mathrm{CXCR} 5^{+}$Bregs can be depleted in vivo by injecting CXCL13 (CXCR5 ligand) that has been coupled to CpG-ODN, and that the remaining $\mathrm{B}$ cells retained the capacity to induce activation of cytotoxic T cells (72). Tao et al. described the use of a blocking antibody against IL-10 to specifically inhibit Bregs and increased the efficiency of CD40-activated B cell transfer, with increased migration of $\mathrm{CD} 8^{+} \mathrm{T}$ cells into the TME and B cell dependent FasL-mediated tumor cell killing (74). Similarly, in a murine breast tumor model, use of the phytoalexin resveratrol induces a decrease in Bregs and reduction in lung metastases (75). Lastly, Lipoxin A4 (LXA4), a metabolite of the arachidonic acid pathway, has been shown to selectively prevent differentiation of Bregs and also Breg-induced Treg differentiation (76).

\section{B cells can predict response to anti-cancer therapies}

Systemic treatment of lung cancer may involve chemotherapy, targeted molecular therapy, or immunotherapy. There have been reports of associations between tumor-infiltrating B cell populations and response to these therapies.

The action of chemotherapies to damage tumor cells may precipitate an immune response that results in therapy resistance. In murine models of squamous cell carcinoma, Affara $e t$ al. demonstrated increased infiltration of immunosuppressive $\mathrm{CD} 20^{+} \mathrm{B}$ cells, which may play a role in resistance to platinum- (cisplatin and carboplatin) and taxol(paclitaxel) based chemotherapy as their removal using an anti-CD20 antibody improved chemoresponsiveness (77).

Targeted molecular therapies act to modulate specific oncogenic pathways. However, despite good initial response rates, a significant proportion of patients will develop resistance. In a study of melanoma treated with inhibitors to oncogenic BRAF mutation, tumor-associated $\mathrm{B}$ cells were observed to mediate drug resistance through secretion of insulin-like growth factor 1 (IGF-1). Furthermore, in therapyresistant metastatic melanoma patients, depletion of $\mathrm{B}$ cells by anti-CD20 antibody may result in tumor control (78).

ICIs have improved cancer treatment by overcoming the inhibition of $\mathrm{T}$ cell effector functions. However, a significant proportion of patients do not respond to such therapies, and there is increasing interest in the impact of B cells upon outcome with ICIs. Supporting this, in the blood of nonprogressing patients with different forms of metastatic cancers (NSCLC, melanoma, renal cell carcinoma) treated with immune checkpoint blockade immunotherapy (antiPD-1 or anti-CTLA4), an active humoral response has been detected with somatic hypermutation, IgG class switch and expansion of anti-tumor plasmablasts (79).

Recently, the presence of B cells have been described as a predictive marker for improved response to immune checkpoint blockade. In studies of melanoma and sarcoma, Helmink et al. and Petitprez et al. respectively demonstrated that the presence of B cells in TLS in the tumor before treatment was associated with increased chance of response to immunotherapy $(80,81)$. Furthermore, these findings were more prominent than typical $\mathrm{T}$ cell signatures that are currently used to guide immunotherapy outcomes. In lung cancer, similar findings of B cell density as predictive of response to checkpoint blockade are yet to be observed. As discussed above characterization and specific investigation of B cells in other solid tumors has revealed avenues for novel application of therapeutics. These findings cannot be directly translated to lung cancer in the absence of the careful characterization of $\mathrm{B}$ cells and subsets proposed in the current review.

Through its activation of the immune system to exert anti-tumor effects, immunotherapy is also associated with multi organ immune-related adverse effects (irAEs) (82). There is early evidence to suggest that B cells may have a potential role as a predictive biomarker for irAEs, where in melanoma patients treated with combination immune checkpoint blockade (with anti-CTLA4 and anti-PD-1 antibodies), patients demonstrating enrichment of specific $\mathrm{B}$ cell populations showed an increased risk of developing irAEs (83). Conversely, B cell depletion using Rituximab has been used successfully to treat irAEs in NSCLC $(84,85)$.

In addition to their capacity as a predictive biomarker to lung cancer treatments, tumor-infiltrating B cells and their immunoglobulin repertoires may have a role in prognostication. One significant example is the association of a high ratio of intratumoral IgG1 to IgA with improved survival in $K R A S$-mutant lung adenocarcinoma (45). Furthermore, abundant IgG4 is associated with a favorable prognosis in lung squamous cell carcinoma (41) and in STK11-mutant and proximal proliferative lung adenocarcinoma (45). Lastly, positive prognosis has been associated with a high ratio of $\mathrm{IgH}$ to $M S 4 A 1$ (which encodes CD20) expression in proximal proliferative lung adenocarcinoma (45).

\section{Future directions}

The phenotypical and functional diversity of B cells make it challenging to clearly define their role in tumor prognosis 
and response to treatment. Few studies that identify B cells in solid tumors have conducted detailed characterization of B cells by developmental status or functionality, instead relying on detection of pan-B cell markers such as CD19 or CD20, which are not constitutively expressed across all maturation and differentiation stages. Furthermore, B cell subtypes may undergo change with the process of metastasis. Therefore, future studies are needed to perform comprehensive profiling of B cell subpopulations in the specific context of the primary TME as well as sites of metastases to unravel the roles of $B$ cells and subsets in promoting early tumor growth and to harness anti-tumor activity.

\section{Conclusions}

The roles of B cells in lung cancer are poorly understood in comparison with $\mathrm{T}$ cells. This is largely due to the phenotypical and functional diversity of tumor-infiltrating $B$ cells, with different B cell subsets exerting anti- and protumor effects. Meticulous and systematic characterization of B cell subpopulations and immunoglobulin repertoires in the TME will yield fundamental insights into the influence of different intratumoral contexts which polarize B cells to these opposing functions. This understanding will identify site-specific B cell infiltrates and unravel the specific intrinsic and extrinsic roles of B cells in contributing to disease pathogenesis to redefine B cells as active participants, and not merely bystanders, in the lung cancer microenvironment.

\section{Acknowledgments}

We thank Associate Professor MLAL for critical review of the manuscript. Manuscript figures were created with BioRender.com.

Funding: None.

\section{Footnote}

Provenance and Peer Review: This article was commissioned by the Guest Editor (Daniel Steinfort) for the series "Lung cancer and the immune system" published in Translational Lung Cancer Research. The article has undergone external peer review.

Reporting Checklist: The authors have completed the Narrative Review reporting checklist. Available at http:// dx.doi.org/10.21037/tlcr-20-788

Peer Review File: Available at http://dx.doi.org/10.21037/ tlcr-20-788

Conflicts of Interest: Both authors have completed the ICMJE uniform disclosure form (available at http://dx.doi. org/10.21037/tlcr-20-788). The series "Lung cancer and the immune system" was commissioned by the editorial office without any funding or sponsorship. TLL reports grants from David Bickart Clinician Researcher Fellowship, outside the submitted work. VLB reports grants from Sir Clive McPherson Family Fellowship, grants from DW Keir Fellowship, grants from NHMRC Project grant 1127198, grants from Homes Foundation, grants from Rae Foundation, grants from Graty family Foundation, grants from MJ Maughan Foundation, grants from Victorian State Government Operational Infrastructure support, outside the submitted work. The authors have no other conflicts of interest to declare.

Ethical Statement: The authors are accountable for all aspects of the work in ensuring that questions related to the accuracy or integrity of any part of the work are appropriately investigated and resolved.

Open Access Statement: This is an Open Access article distributed in accordance with the Creative Commons Attribution-NonCommercial-NoDerivs 4.0 International License (CC BY-NC-ND 4.0), which permits the noncommercial replication and distribution of the article with the strict proviso that no changes or edits are made and the original work is properly cited (including links to both the formal publication through the relevant DOI and the license). See: https://creativecommons.org/licenses/by-nc-nd/4.0/.

\section{References}

1. Bray F, Ferlay J, Soerjomataram I, et al. Global cancer statistics 2018: GLOBOCAN estimates of incidence and mortality worldwide for 36 cancers in 185 countries. CA Cancer J Clin 2018;68:394-424.

2. Siegel RL, Miller KD, Jemal A. Cancer statistics, 2020. CA Cancer J Clin 2020;70:7-30.

3. Scagliotti GV, Bironzo P, Vansteenkiste JF. Addressing the unmet need in lung cancer: the potential of immuneoncology. Cancer Treat Rev 2015;41:465-75.

4. Kataki A, Scheid P, Piet M, et al. Tumor infiltrating 
lymphocytes and macrophages have a potential dual role in lung cancer supporting both host-defense and tumor progression. J Lab Clin Med 2002;140:320-8.

5. Wei SC, Levine JH, Cogdill AP, et al. Distinct cellular mechanisms underlie anti-CTLA-4 and anti-PD-1 checkpoint blockade. Cell 2017;170:1120-33.e17.

6. Borst J, Ahrends T, Babala N, et al. CD4+ T cell help in cancer immunology and immunotherapy. Nat Rev Immunol 2018;18:635-47.

7. Datta M, Coussens LM, Nishikawa H, et al. Reprogramming the TME to improve immunotherapy: emerging strategies and combination therapies. Am Soc Clin Oncol Educ Book 2019;39:165-74.

8. Gottlin EB, Bentley RC, Campa MJ, et al. The association of intratumoral germinal centers with early-stage nonsmall cell lung cancer. J Thorac Oncol 2011;6:1687-90.

9. Banat GA, Tretyn A, Pullamsetti SS, et al. Immune and inflammatory cell composition of human lung cancer stroma. PLoS One 2015;10:e0139073.

10. Kurebayashi Y, Emoto K, Hayashi Y, et al. Comprehensive immune profiling of lung adenocarcinoma reveals four immunosubtypes with plasma cell subtype a negative indicator. Cancer Immunol Res 2016;4:234-47.

11. Largeot A, Pagano G, Gonder S, et al. The B-side of cancer immunity: the underrated tune. Cells 2019;8:449-69.

12. Nelson BH. CD20+ B cells: the other tumor-infiltrating lymphocytes. J Immunol 2010;185:4977-82.

13. Jacob J, Miller C, Kelsoe. In situ studies of the antigendriven somatic hypermutation of immunoglobulin genes. Immunol Cell Biol 1992;70:145-52.

14. Neuberger MS, Milstein C. Somatic hypermutation. Curr Opin Immunol 1995;7:248-54.

15. Stavnezer J, Bradley SP, Rousseau N, et al. Switch recombination in a transfected plasmid occurs preferentially in a B cell line that undergoes switch recombination of its chromosomal Ig heavy chain genes. J Immunol 1999;163:2028-40.

16. Roco JA, Mesin L, Binder SC, et al. Class-switch recombination occurs infrequently in germinal centers. Immunity 2019;51:337-50.e7.

17. Germain C, Gnjatic S, Tamzalit F, et al. Presence of B cells in tertiary lymphoid structures is associated with protective immunity in patients with lung cancer. Am J Respir Crit Care Med 2014;189:832-44.

18. Crotty S, Kersh EN, Cannons J, et al. SAP is required for generating long-term humoral immunity. Nature 2003;421:282-7.

19. McHeyzer-Williams MG, Ahmed R. B cell memory and the long-lived plasma cell. Curr Opin Immunol 1999;11:172-9.

20. Schwartz M, Zhang Y, Rosenblatt JD. B cell regulation of the anti-tumor response and role in carcinogenesis. J Immunother Cancer 2016;4:40-55.

21. Sarvaria A, Madrigal JA, Saudemont A. B cell regulation in cancer and anti-tumor immunity. Cell Mol Immunol 2017;14:662-74.

22. Shen M, Wang J, Ren X. New insights into tumorinfiltrating B lymphocytes in breast cancer: clinical impacts and regulatory mechanisms. Front Immunol 2018;9:470.

23. Chiaruttini G, Mele S, Opzoomer J, et al. B cells and the humoral response in melanoma: the overlooked players of the tumor microenvironment. Oncoimmunology 2017;6:e1294296.

24. Vilgelm AE, Richmond A. Chemokines modulate immune surveillance in tumorigenesis, metastasis, and response to immunotherapy. Front Immunol 2019;10:333.

25. Mollica Poeta V, Massara M, Capucetti A, et al. Chemokines and chemokine receptors: new targets for cancer immunotherapy. Front Immunol 2019;10:379.

26. Wouters MCA, Nelson BH. Prognostic significance of tumor-infiltrating B cells and plasma cells in human cancer. Clin Cancer Res 2018;24:6125-35.

27. Al-Shibli KI, Donnem T, Al-Saad S, et al. Prognostic effect of epithelial and stromal lymphocyte infiltration in non-small cell lung cancer. Clin Cancer Res 2008;14:5220-7.

28. Kinoshita T, Muramatsu R, Fujita T, et al. Prognostic value of tumor-infiltrating lymphocytes differs depending on histological type and smoking habit in completely resected non-small-cell lung cancer. Ann Oncol 2016;27:2117-23.

29. Zhu W, Germain C, Liu Z, et al. A high density of tertiary lymphoid structure B cells in lung tumors is associated with increased CD4+ T cell receptor repertoire clonality. Oncoimmunology 2015;4:e1051922.

30. Sautès-Fridman C, Petitprez F, Calderaro J, et al. Tertiary lymphoid structures in the era of cancer immunotherapy. Nat Rev Cancer 2019;19:307-25.

31. Iwata Y, Matsushita T, Horikawa M, et al. Characterization of a rare IL-10-competent B-cell subset in humans that parallels mouse regulatory B10 cells. Blood 2011;117:530-41.

32. Ganti S, Albershardt T, Iritani B, et al. Regulatory B cells accumulate in tumor-draining lymph nodes and promote tumor growth (TUM9P.1015). J Immunol 2015;194:210-7.

33. Flores-Borja F, Bosma A, Ng D, et al. CD19+ CD24hi 
CD38hi B cells maintain regulatory T cells while limiting TH1 and TH17 differentiation. Sci Transl Med 2013;5:173ra23.

34. Lindner S, Dahlke K, Sontheimer K, et al. Interleukin 21-induced granzyme B-expressing cells infiltrate tumors and regulate T cells. Cancer Res 2013;73:2468-79.

35. van de Veen W, Stanic B, Yaman G, et al. IgG4 production is confined to human IL-10-producing regulatory B cells that suppress antigen-specific immune responses. J Allergy Clin Immunol 2013;131:1204-12.

36. Iglesia MD, Parker JS, Hoadley KA, et al. Genomic analysis of immune cell infiltrates across 11 tumor types. J Natl Cancer Inst 2016;108:djw144.

37. Ho KH, Chang CJ, Huang TW, et al. Gene landscape and correlation between B-cell infiltration and programmed death ligand 1 expression in lung adenocarcinoma patients from The Cancer Genome Atlas data set. PLoS One 2018;13:e0208459.

38. Rodríguez-Pinto D. B cells as antigen presenting cells. Cell Immunol 2005;238:67-75.

39. Rubtsov AV, Rubtsova K, Kappler JW, et al. CD11cexpressing B cells are located at the T cell/B cell border in spleen and are potent APCs. J Immunol 2015;195:71-9.

40. Bruno TC, Ebner PJ, Moore BL, et al. Antigen-presenting intratumoral B cells affect CD4+ TIL phenotypes in nonsmall cell lung cancer patients. Cancer Immunol Res 2017;5:898-907.

41. Fujimoto M, Yoshizawa A, Sumiyoshi S, et al. Stromal plasma cells expressing immunoglobulin G4 subclass in non-small cell lung cancer. Hum Pathol 2013;44:1569-76.

42. Mizukami M, Hanagiri T, Yasuda M, et al. Antitumor effect of antibody against a SEREX-defined antigen (UOEH-LC-1) on lung cancer xenotransplanted into severe combined immunodeficiency mice. Cancer Res 2007;67:8351-7.

43. Carmi Y, Spitzer MH, Linde IL, et al. Allogeneic IgG combined with dendritic cell stimuli induce antitumor T-cell immunity. Nature 2015;521:99-104.

44. Schroeder HW Jr, Cavacini L. Structure and function of immunoglobulins. J Allergy Clin Immunol 2010;125:S41-52.

45. Isaeva OI, Sharonov GV, Serebrovskaya EO, et al. Intratumoral immunoglobulin isotypes predict survival in lung adenocarcinoma subtypes. J Immunother Cancer 2019;7:279.

46. Hald SM, Bremnes RM, Al-Shibli K, et al. CD4/CD8 co-expression shows independent prognostic impact in resected non-small cell lung cancer patients treated with adjuvant radiotherapy. Lung Cancer 2013;80:209-15.

47. Suzuki K, Kadota K, Sima CS, et al. Clinical impact of immune microenvironment in stage I adenocarcinoma: tumor interleukin-12 receptor $\beta 2$ (IL-12R $\beta 2$ ), IL-7R, and stromal FoxP3/CD3 ratio are independent predictors of recurrence. J Clin Oncol 2013;31:490-8.

48. de Visser KE, Korets LV, Coussens LM. De novo carcinogenesis promoted by chronic inflammation is B lymphocyte dependent. Cancer Cell 2005;7:411-23.

49. Inoue S, Leitner WW, Golding B, et al. Inhibitory effects of B cells on antitumor immunity. Cancer Res 2006;66:7741-7.

50. Tan TT, Coussens LM. Humoral immunity, inflammation and cancer. Curr Opin Immunol 2007;19:209-16.

51. Bodogai M, Moritoh K, Lee-Chang C, et al. Immunosuppressive and prometastatic functions of myeloid-derived suppressive cells rely upon education from tumor-associated B cells. Cancer Res 2015;75:3456-65.

52. Patel AJ, Richter A, Drayson MT, et al. The role of B lymphocytes in the immune-biology of non-small-cell lung cancer. Cancer Immunol Immunother 2020;69:325-42.

53. Yang C, Lee H, Pal S, et al. B cells promote tumor progression via STAT3 regulated-angiogenesis. PLoS One 2013;8:e64159.

54. Yang J, Yan J, Liu B. Targeting VEGF/VEGFR to modulate antitumor immunity. Front Immunol 2018;9:978.

55. Zhou J, Min Z, Zhang D, et al. Enhanced frequency and potential mechanisms of Bregulatory cells in patients with lung cancer. J Transl Med 2014;12:304.

56. Fillatreau S. Regulatory plasma cells. Curr Opin Pharmacol 2015;23:1-5.

57. Balkwill F, Montfort A, Capasso M. B regulatory cells in cancer. Trends Immunol 2013;34:169-73.

58. Mauri C, Menon M. The expanding family of regulatory $\mathrm{B}$ cells. Int Immunol 2015;27:479-86.

59. Lizotte PH, Ivanova EV, Awad MM, et al. Multiparametric profiling of non-small-cell lung cancers reveals distinct immunophenotypes. JCI Insight 2016;1:e89014.

60. Zhang $\mathrm{C}$, Xin H, Zhang W, et al. CD5 binds to interleukin- 6 and induces a feed-forward loop with the transcription factor STAT3 in B cells to promote cancer. Immunity 2016;44:913-23.

61. Ma QY, Chen J, Zhao J. Follicular cytotoxic CD8 T cells present high cytokine expression, and are more susceptible to Breg-mediated suppression in non-small cell lung cancer. Immunol Res 2020;68:54-62. 
62. Sautès-Fridman C, Cherfils-Vicini J, Damotte D, et al. Tumor microenvironment is multifaceted. Cancer Metastasis Rev 2011;30:13-25.

63. Litsiou E, Semitekolou M, Galani IE, et al. CXCL13 production in B cells via toll-like receptor/lymphotoxin receptor signaling is involved in lymphoid neogenesis in chronic obstructive pulmonary disease. Am J Respir Crit Care Med 2013;187:1194-202.

64. Hendriks D, Choi G, de Bruyn M, et al. Antibody-based cancer therapy: successful agents and novel approaches. Int Rev Cell Mol Biol 2017;331:289-383.

65. Vansteenkiste JF, Cho BC, Vanakesa T, et al. Efficacy of the MAGE-A3 cancer immunotherapeutic as adjuvant therapy in patients with resected MAGE-A3-positive nonsmall-cell lung cancer (MAGRIT): a randomised, doubleblind, placebo-controlled, phase 3 trial. Lancet Oncol 2016;17:822-35.

66. Gonzalez NK, Wennhold K, Balkow S, et al. In vitro and in vivo imaging of initial B-T-cell interactions in the setting of B-cell based cancer immunotherapy. Oncoimmunology 2015;4:e1038684.

67. Sorrentino R, Morello S, Forte G, et al. B cells contribute to the antitumor activity of $\mathrm{CpG}$-oligodeoxynucleotide in a mouse model of metastatic lung carcinoma. Am J Respir Crit Care Med 2011;183:1369-79.

68. Barbera-Guillem E, Nelson MB, Barr B, et al. B lymphocyte pathology in human colorectal cancer. Experimental and clinical therapeutic effects of partial $B$ cell depletion. Cancer Immunol Immunother 2000;48:541-9.

69. Winkler JK, Schiller M, Bender C, et al. Rituximab as a therapeutic option for patients with advanced melanoma. Cancer Immunol Immunother 2018;67:917-24.

70. Theurich S, Schlaak M, Steguweit H, et al. Targeting tumor-infiltrating B cells in cutaneous T-cell lymphoma. J Clin Oncol 2016;34:e110-6.

71. DiLillo DJ, Yanaba K, Tedder TF. B cells are required for optimal CD4+ and CD8+ T cell tumor immunity: therapeutic B cell depletion enhances B16 melanoma growth in mice. J Immunol 2010;184:4006-16.

72. Bodogai M, Lee Chang C, Wejksza K, et al. Anti-CD20 antibody promotes cancer escape via enrichment of tumor- evoked regulatory B cells expressing low levels of CD20 and CD137L. Cancer Res 2013;73:2127-38.

73. Rosser EC, Mauri C. Regulatory B cells: origin, phenotype, and function. Immunity 2015;42:607-12.

74. Tao H, Lu L, Xia Y, et al. Antitumor effector B cells directly kill tumor cells via the Fas/FasL pathway and are regulated by IL-10. Eur J Immunol 2015;45:999-1009.

75. Lee-Chang C, Bodogai M, Martin-Montalvo A, et al. Inhibition of breast cancer metastasis by resveratrolmediated inactivation of tumor-evoked regulatory B cells. J Immunol 2013;191:4141-51.

76. Wang Z, Cheng Q, Tang K, et al. Lipid mediator lipotoxin A4 inhibits tumor growth by targeting IL-10-producing regulatory B (Breg) cells. Cancer Lett 2015;364:118-24.

77. Affara NI, Ruffell B, Medler TR, et al. B cells regulate macrophage phenotype and response to chemotherapy in squamous carcinomas. Cancer Cell 2014;25:809-21.

78. Somasundaram R, Zhang G, Fukunaga-Kalabis M, et al. Tumor-associated B-cells induce tumor heterogeneity and therapy resistance. Nat Commun 2017;8:607.

79. DeFalco J, Harbell M, Manning-Bog A, et al. Nonprogressing cancer patients have persistent $\mathrm{B}$ cell responses expressing shared antibody paratopes that target public tumor antigens. Clin Immunol 2018;187:37-45.

80. Helmink BA, Reddy SM, Gao J, et al. B cells and tertiary lymphoid structures promote immunotherapy response. Nature 2020;577:549-55.

81. Petitprez F, de Reyniès A, Keung EZ, et al. B cells are associated with survival and immunotherapy response in sarcoma. Nature 2020;577:556-60.

82. Winer A, Bodor JN, Borghaei H. Identifying and managing the adverse effects of immune checkpoint blockade. J Thorac Dis 2018;10:S480-9.

83. Das R, Bar N, Ferreira M, et al. Early B cell changes predict autoimmunity following combination immune checkpoint blockade. J Clin Investig 2018;128:715-20.

84. Sowerby L, Dewan AK, Granter S, et al. Rituximab treatment of nivolumab-induced bullous pemphigoid. JAMA Dermatol 2017;153:603-5.

85. Shaikh H, Daboul N, Albrethsen M, et al. A case of autoimmune haemolytic anaemia after 39 cycles of nivolumab. BMJ Case Rep 2018;2018:bcr201822460.
Cite this article as: Leong TL, Bryant VL. B cells in lung cancer-not just a bystander cell: a literature review. Transl Lung Cancer Res 2021;10(6):2830-2841. doi: 10.21037/tlcr20-788 